\title{
Pediatric Respiratory Assembly
}

\author{
Mini symposium on lung inflammation
}

\section{Regulation of inflammation in lung disease}

\author{
Larry C Lands MD PhD \\ Professor of Pediatrics, McGill University, \\ Montréal, Québec
}

\begin{abstract}
A $s$ an introduction to the symposium, the present article briefly reviews some of the topics pertinent to inflammatory lung disease in children.

The respiratory tract is exposed to a variety of infectious pathogens and a variety of oxidants. Examples of exogenous oxidant sources include air pollution and cigarette smoke, while endogenous oxidants are those produced by neutrophils when killing bacteria with an oxidative burst. An overabundance of neutrophils, as is the case in cystic fibrosis, can overwhelm the antioxidant network.

There are also a variety of defense mechanisms, including the mucus barrier and ciliary clearance, and a host of cellular players. The cellular system consists of cells involved in innate immunity including macrophages, neutrophils, and respiratory epithelial cells and adaptive immune cells - primarily lymphocytes (1). Dendritic cells, which recognize antigens through pattern recognition receptors such as toll-like receptors, bridge the two systems. Dendritic cells populate epithelial surfaces and, after binding antigen, mature and migrate to the lymph nodes where they stimulate B and T cells. The simple model of T-helper (Th) 1 and 2, and T suppressor lymphocytes has been eclipsed by a more nuanced model that involves a complex system of lymphocytes (2). Finally, to limit the propagation of inflammation, there are stop signals such as lipoxins that promote the resolution of acute inflammatory responses (3).

Neutrophils leave the circulation and migrate into mucosal and luminal spaces as a result of changes in the expression of endothelial adhesion factors and surface ligands on the neutrophilic surface (4). Neutrophils follow cytokine gradients to the site of action (5).

Phagocytes, such as macrophages and neutrophils, ingest pathogens. However, bacterial killing requires an oxidative burst for the production of the superoxide radical (6). Superoxide can undergo dismutation to form hydrogen
\end{abstract}

peroxide. It can also combine with hydrogen peroxide to form the particularly potent hydroxyl radical, or be transformed by myeloperoxidase to form hypochlorous acid, otherwise known as bleach. Within the phagocyte, superoxide promotes alkalinization of the cytoplasm, leading to the release of cationic granule proteins in the lysosome that are toxic to the ingested bacteria (7).

The other significant radical species are reactive nitrogen species, particularly nitric oxide. Nitric oxide is produced by a variety of tissues, but in particular, the respiratory epithelium. Nitric oxide can combine with superoxide to form peroxynitrite, which can be particularly damaging to proteins. To limit formation of peroxynitrite, there is generally an increase in superoxide dismutase activity to limit superoxide availability when nitric oxide synthetase activity is increased.

With inflammatory responses, there is a release of a variety of reactive oxygen and nitrogen species. These require counterbalancing by an integrated antioxidant network, which combines enzymes and dietary-derived antioxidants. In relinquishing the sessile life of plants, humans developed the ability to acquire many antioxidants such as vitamins $\mathrm{C}, \mathrm{E}$ and betacarotene through the ingestion of plants and vegetables rich in these compounds. The network operates in a coordinated fashion: nuclear factor-E2-related factor-2 is a transcription factor promoting dozens of enzymes and proteins involved in antioxidant and detoxifying defenses (8). The network is also compartmentalized, with factors such as vitamin E protecting membranes, while others are more cytoplasmic or extracellular, or particularly found in locations of high oxidant activity. For example, glutathione is a ubiquitously produced tripeptide found in high abundance in the surface of the lung lining, where there is a high concentration of exogenous and endogenous oxidants, and within the mitochondria where oxygen radicals are formed as a byproduct of oxidative ATP production.

Reactive oxygen and nitrogen species can also act as signalling molecules that can activate transcription factors such as nuclear factor-kappa B and activating protein-1 (AP-1) $(9,10)$. These factors bind to promoter regions giving rise to inflammatory stimuli and also to factors that regulate their activation (11). Thus, both positive and negative feedback loops exist.

One of the most significant processes linking oxidative stress to gene expression is glutathionylation (12). Certain sensitive protein moieties, such as cysteine residues, are susceptible to oxidation. When cysteine is oxidized, it forms a 
cysteine double bond, resulting in changes to protein structure and function. To prevent this from occurring, glutathione will transiently bind to these moieties. Although this transiently changes protein structure and function, it does so to a much lesser extent than permanent oxidation. For instance, glutathionylation of the cysteine residue of the AP-1 binding site reduces AP-1 binding to promoter regions. Through glutathionylation, the availability of glutathione and the relative abundance of oxidized to reduced glutathione have a significant impact on gene expression.

Two examples are worth illustrating. Mice that were incapable of antibody responses, in which glutathione levels were reduced in only the antigen presenting cells, were able to mount an antibody response and had a relative rise in Th2 response (13). In a second example, a virus that normally did not provoke myocarditis in mice became pathogenic after being propagated in selenium-deficient mice (14). Selenium is a required cofactor for glutathione scavenging of oxidants. While it is unclear what led to the transformation of the virus into a more virulent form, there is a clinical equivalent: Keshan disease refers to a region of China where the soil and, consequently, the fruits and vegetables, are selenium poor. The introduction of selenium supplementation in Keshan province resulted in a dramatic decrease in the previously high incidence of myocarditis.

\section{SUMMARY}

Inflammatory responses require sentinel and effector cells. Reactive oxygen and nitrogen species have antimicrobial properties and are important in cell signalling and modulation of the immune response.

\section{REFERENCES}

1. Nathan C. Points of control in inflammation. Nature 2002;42:846-52.

2. LaRosa DF, Orange JS. 1. Lymphocytes. J Allergy and Clin Immunol 2008;121(Suppl 2):S364-S369.

3. Haworth O, Levy BD. Endogenous lipid mediators in the resolution of airway inflammation. Eur Respir J 2007;30:980-92.

4. Guo RF, Ward PA. Mediators and regulation of neutrophil accumulation in inflammatory responses in lung: Insights from the IgG immune complex model. Free Radic Biol Med 2002;33:303-10.

5. Guo RF, Ward PA. Role of oxidants in lung injury during sepsis. Antioxid Redox Signal 2007;9:1991-2002.

6. Van der Vliet A, Cross CE. Oxidants, nitrosants, and the lung. Am J Med 2000;109:398-421.

7. Reeves EP, Lu H, Jacobs HL, et al. Killing activity of neutrophils is mediated through activation of proteases by $\mathrm{K}^{+}$flux. Nature 2002;416:291-7.

8. Jaiswal AK. Nrf2 signaling in coordinated activation of antioxidant gene expression. Free Radic Biol Med 2004;36:1199-207.

9. Bowie A, O’Neill LA. Oxidative stress and nuclear factor-kappaB activation: A reassessment of the evidence in the light of recent discoveries. Biochem Pharmacol 2000;59:13-23.

10. Barnes PJ, Karin M. Nuclear factor-kappaB: A pivotal transcription factor in chronic inflammatory diseases. N Eng J Med 1997;336:1066-71.

11. MacDonald J, Galley HF, Webster NR. Oxidative stress and gene expression in sepsis. Br J Anaesth 2003;90:221-32.

12. Klatt P, Molina EP, De Lacoba MG, et al. Redox regulation of c-Jun DNA binding by reversible S-glutathiolation. FASEB J 1999;13:1481-90.

13. Peterson JD, Herzenberg LA, Vasquez K, Waltenbaugh C. Glutathione levels in antigen-presenting cells modulate Th1 versus Th2 response patterns. Proc Natl Acad Sci USA 1998;95:3071-6.

14. Beck MA, Levander OA. Host nutritional status and its effect on a viral pathogen. J Infect Dis 2000;182(Suppl 1):S93-S96.

\section{Inflammation in bronchopulmonary dysplasia}

\author{
A Keith Tanswell MD \\ Division of Neonatology, Hospital for Sick \\ Children, Toronto, Ontario
}

$\mathrm{B}_{\mathrm{s}}^{\mathrm{r}}$ ronchopulmonary dysplasia (BPD) in the modern era is characterized by arrested or inhibited alveolar formation with interstitial thickening (1) and, in the most severe cases, pulmonary hypertension (2). Contributors to the development of BPD include chorioamnionitis (3), sepsis (4), hyperoxia and, probably, ventilation-induced volutrauma. That hyperoxia should be included in this list, in an era in which surfactant therapy in the delivery room usually results in a minimal need for oxygen supplementation, is not intuitively obvious. However, trials aimed at reducing the incidence of retinopathy of prematurity by maintaining preterm infants' oxygen saturations above $95 \%$ to $96 \%$ resulted in an increased incidence of $\operatorname{BPD}(5,6)$. Given that variations in this range are commonly observed in neonatal intensive care units (NICUs), hyperoxia almost certainly continues to contribute to the development of $\mathrm{BPD}$. There is ample evidence that grossly excessive tidal volumes can cause lung injury. What is lacking are human data to support a role for ventilation-induced lung injury at the tidal volumes normally used in clinical practice within an NICU. However, there is good evidence from studies in preterm lambs using a tidal volume of $5 \mathrm{~mL} / \mathrm{kg}$ versus $15 \mathrm{~mL} / \mathrm{kg}$ (7).

What all of these contributors have in common is that they induce an inflammatory response. Activated phagocytes generate reactive oxygen and nitrogen species that can induce growth arrest through activation of cyclin-dependent kinase inhibitors following cell injury or can inhibit lung cell growth through redox regulation. There are no studies that used specific therapies to target phagocytes in human neonates; thus, we are forced to extrapolate from animal models. The animal model of BPD used in my laboratory is the neonatal rat exposed to $60 \%$ oxygen for 14 days, which results in a lung pathology closely resembling that observed in human BPD (8). In this model, approximately two-thirds of the increased generation of reactive oxygen species observed following exposure to $60 \%$ oxygen can be attributed to phagocyte influx, initially from neutrophils and, subsequently, from macrophages (9). Inhibition of the macrophage influx by treatment with gadolinium chloride had no effect on gross lung morphology but completely prevented the development of pulmonary hypertension (10). When the neutrophil influx was prevented by treatment with a cytokine-induced neutrophil chemoattractant-1 receptor antagonist, interstitial thickening was prevented and, in the absence of inflammation, oxygen-enhanced alveolar formation increased by $60 \%$ (9). Inhibition of the neutrophil influx also protected against vascular pruning (11).

For several decades, neonatologists have used dexamethasone to suppress inflammation in neonates with evolving BPD (12). This therapeutic approach is no longer recommended for routine use based on associated adverse neurodevelopmental outcomes (13), and there is currently no therapeutic 
alternative available. Complete, sustained inhibition of a neutrophil influx is not a feasible therapeutic option for the preterm infant who is already immunocompromised. Therefore, we have examined other potential therapeutic options to dampen the inflammatory response in this particular neonatal rat model of BPD. Dexamethasone has many effects, one of which is a potent cyclooxygenase-2 (COX-2) inhibitor. COX-2 expression is markedly upregulated in the neonatal rat model (14). Treatment of rat pups with a specific COX-2 inhibitor prevents phagocyte influx during lung injury and prevents lung interstitial thickening, but has the unfortunate side effect of independently arresting alveolar formation (15), making it an unsuitable therapeutic approach. Passive or therapeutic hypercapnia has engendered considerable recent interest as an approach to the prevention of lung injury. When applied to the neonatal rat model of BPD, a target partial pressure of carbon dioxide of approximately $70 \mathrm{mmHg}$ completely prevented the macrophage influx, significantly reduced the neutrophil influx, and prevented both interstitial thickening and vascular pruning (16). These findings reinforce the critical role of inflammation in neonatal lung injury. However, as useful as therapeutic hypercapnia may become in older patients, its use in the neonate may not be possible due to increased risks of cortical and retinal injury. In chorioamnionitis, the amniotic fluid contains the proinflammatory cytokine interleukin (IL)-1 beta (IL-1 $\beta$ ), the presence of which has been correlated with the development of BPD (17). Overexpression of IL-1 $\beta$ in neonatal mice results in a BPDlike lung pathology (18). The expression of both IL-1 alpha and IL- $1 \beta$ are upregulated in the neonatal rat model of BPD, and blocking the effects of these cytokines with an IL-1 receptor antagonist prevents the neutrophil influx and interstitial thickening and, thus, restores alveolar formation (19).

\section{SUMMARY}

Existing evidence is consistent with BPD being mediated by inflammation, to which multiple clinical factors may contribute. Evidence from a small animal model of BPD suggest that therapeutic strategies that target inflammation have the potential to attenuate or reverse chronic neonatal lung injury.

\section{REFERENCES}

1. Coalson JJ. Pathology of chronic lung disease of early infancy. In: Bland RD, Coalson JJ, eds. Chronic Lung Disease of Early Infancy. New York: Dekker, 2000:85-124.

2. Abman SH. Pulmonary hypertension in chronic lung disease of infancy: Pathogenesis, pathophysiology, and treatment. In: Bland RD, Coalson JJ, eds. Chronic Lung Disease of Early Infancy. New York: Dekker, 2000:619-68.

3. Watterberg KL, Demers LM, Scott SM, Murphy S. Chorioamnionitis and early lung inflammation in infants in whom bronchopulmonary dysplasia develops. Pediatrics 1996;97:210-5.

4. Bancalari E, Gonzales A. Clinical course and lung function abnormalities during development of neonatal chronic lung. In: Bland RD, Coalson JJ, eds. Chronic Lung Disease of Early Infancy. New York: Dekker, 2000:41-64.

5. STOP-ROP Multicenter Study Group. Supplemental therapeutic oxygen for prethreshold retinopathy of prematurity (STOP-ROP), a randomized, controlled trial. I: Primary outcomes. Pediatrics 2000;105:295-310.

6. Askie LM, Henderson-Smart DJ, Irwig L, Simpson JM. Oxygensaturation targets and outcomes in extremely preterm infants. New Eng J Med 2003;349:959-67.

7. Albertine $\mathrm{KH}$, Jones GP, Starcher BC, et al. Chronic lung injury in preterm lambs. Disordered respiratory tract development. Am J Respir Crit Care Med 1999;59:945-58.
8. Han RNN, Buch S, Tseu I, et al. Changes in structure, mechanics, and insulin-like growth factor-related gene expression in the lungs of newborn rats exposed to 60\% oxygen. Pediatr Res 1996;39:921-9.

9. Yi M, Jankov RP, Belcastro R, et al. Opposing effects of $60 \%$ oxygen and neutrophil influx on alveologenesis in the neonatal rat. Am J Respir Crit Care Med 2004:170:1188-96.

10. Jankov RP, Luo X, Belcastro R, et al. Gadolinium chloride inhibits pulmonary macrophage influx and prevents $\mathrm{O}_{2}$-induced pulmonary hypertension in the neonatal rat. Pediatr Res 2001;50:172-83.

11. Yi M, Masood A, Jankov RP, Tanswell AK. Inhibition of neutrophil influx protects against vessel loss in $60 \%$ oxygen-induced neonatal rat lung injury. E-PAS 2008;63:4850.3. (Abst)

12. Bhuta T, Ohlsson A. Systematic review and meta-analysis of early postnatal dexamethasone for prevention of chronic lung disease. Arch Dis Child 1998;79:F26-F33.

13. Committee on Fetus and Newborn of the American Academy of Pediatrics and the Fetus and Newborn Committee of the Canadian Paediatric Society. Postnatal corticosteroids to treat or prevent chronic lung disease in preterm infants. Pediatrics 2002;109:330-8.

14. Jankov RP, Belcastro R, Ovcina E, et al. Thromboxane $A_{2}$ receptors mediate pulmonary hypertension in $60 \%$ oxygen-exposed newborn rats by a cyclooxygenase-independent mechanism. Am J Respir Crit Care Med 2002;166:208-14.

15. Ziino AJA, Tanswell AK. Selective COX-2 inhibition prevents $60 \% \mathrm{O}_{2}$-mediated interstitial thickening, but at the cost of impaired alveolar formation. Proc Am Thorac Soc 2006;2:A39. (Abst)

16. Masood A, Jankov RP, Yi M, et al. Therapeutic hypercapnia protects against chronic neonatal lung injury, and prevents vascular remodeling in the neonatal rat. E-PAS 2007;61:6291-7.

17. Yoon BH, Romero R, Jun JK, Park JD, Ghezzi F, Kim BI. Amniotic fluid cytokines (interleukin-6, tumor necrosis factor-alpha, interleukin-1 beta, and interleukin-8) and the risk for developing bronchopulmonary dysplasia. Am J Obstet Gynecol 1997;177:825-30.

18. Bry K, Whitsett JA, Lappalainen U. IL-1 beta disrupts postnatal lung morphogenesis in the mouse. Am J Respir Cell Mol Biol 2007;36:32-42.

19. Johnson BH, Yi M, Shek S, et al. Role of IL-1 in the neonatal model of chronic lung injury induced by exposure to $60 \%$ oxygen. E-PAS 2007;61:5894-9. (Abst)

\section{Inflammatory phenotypes in childhood asthma}

\author{
Sophie Laberge MD \\ Division of Pediatric Respiratory Medicine \\ Hôpital Ste-Justine, Montréal, Québec
}

$\mathrm{D}$ ifferent inflammatory phenotypes have been identified in adults with asthma (1). Eosinophilic asthma is associated with atopy, predominant T-helper (Th) cell 2 cytokine production and the development of exacerbations that respond to corticosteroids, whereas neutrophilic asthma is associated with severe disease, with a general lack of responsiveness to corticosteroids. Doubt exists as to whether all asthma in children has a similar basis to chronic asthma in adults. The study of inflammatory patterns in childhood asthma may help to understand the relationship between symptoms, lung function and inflammation; help to clarify the natural history of the disease by elucidating etiological pathways and the relationship between inflammation and airway remodelling; and help guide the management of asthma by optimizing treatment for individual patients and by monitoring response to treatment.

Noninvasive and invasive methods to assess airway inflammation sample different compartments, and data from these samples cannot been used interchangeably $(2,3)$. As such, neutrophil numbers are higher in induced sputum (IS) compared with 
bronchoalveolar lavage (BAL) and endobronchial biopsies (EBBs) (4). BAL eosinophil numbers correlate with IS eosinophil numbers, but there is no correlation between either IS or BAL eosinophil numbers and mucosal eosinophils (5). Exhaled nitric oxide (NO) correlates with IS and BAL eosinophil numbers but not with mucosal eosinophils, indicating that fractional exhaled nitric oxide reflects luminal eosinophilic inflammation (5). Fractional exhaled $\mathrm{NO}$ is mainly a marker of atopy that correlates poorly to clinical symptoms and lung function in asthmatic children (6). Most studies in childhood asthma are case control and cross-sectional, involving small numbers of patients. There are sparse data regarding mucosal inflammation and mediator expression assessed by EBBs (7-16). Comparisons between studies are limited given the heterogeneity in the study population, and the underlying treatment and technical differences in the various methods used to assess inflammation.

In school-age children with mild to moderate asthma, numbers of mucosal eosinophils are higher than in atopic children without asthma and in healthy controls $(12,13)$. In asthmatic patients, musosal eosinophil numbers correlate with symptom duration. Asthmatic individuals have decreased numbers of transforming growth factor (TGF)-beta receptor 2-positive cells compared with healthy controls, suggesting that TGFbeta signalling may be downregulated in asthma. Interestingly, mucosal eosinophil numbers are higher in atopic children than in normal controls, suggesting that allergic sensitization itself may be associated with airway eosinophilia and that eosinophils themselves are not sufficient for the development of asthma (12). Using EBBs, Barbato et al (13) have recently shown that atopic and nonatopic asthmatic individuals do not differ in the magnitude of eosinophil infiltration, the expression of interleukin (IL)-4 and IL-5, and features of airway remodelling, suggesting some similarities in airway pathology between these two groups of subjects (Barbato, in press). Airway eosinophilia, T cell activation, Th2 cytokine activation and features of airway remodelling persist in patients with clinical remission of atopic asthma $(17,18)$. In school-age children with difficult asthma requiring large doses of inhaled corticosteroids, the numbers of $\mathrm{CD}^{+}{ }^{+} \mathrm{T}$ cells are higher in patients with persistent airflow limitation compared with patients without persistent airflow limitation following therapy with systemic steroids (10); there is a significant correlation between $\mathrm{CD}^{+} \mathrm{T}$ cell infiltration and forced expiratory volume in $1 \mathrm{~s}$ values, suggesting that failure to achieve normal lung function after steroid therapy is associated with an impaired ability to suppress $\mathrm{T}$ cell activation. Consistent with this, de Blic et al (8) have shown that patients with difficult asthma with symptomatic, persistent, airway obstruction had lower interferon (IFN)gamma expression and IFN-gamma/IL-4 ratio than patients who had persistent airflow obstruction but fewer symptoms.

In preschoolers, viral-associated wheeze is not associated with airway eosinophilia $(19,20)$. In some, but not all studies, neutrophils predominated in BAL fluid specimens from these patients $(20,21)$, and neutrophil counts were higher in BAL specimens retrieved from subjects with positive bacterial BAL cultures. These findings suggest that infectious processes, either viral or bacterial, may contribute to the pathogenesis of wheezing in this age group. Neutrophil-mediated inflammation, in the absence of infection, may also contribute to asthma pathology in these subjects. Krawiec et al (22) investigated the inflammatory profile of a group of very young patients with recurrent or prolonged wheezing, most of them with atopy and a clinical bronchodilator response to salbutamol; patients were excluded if viral or bacterial BAL cultures were found to be positive. In these patients with 'probable asthma', the cellular profile showed a nonspecific inflammatory response, reflected by an increase in all cell types, including airway epithelial cells, compared with normal controls, which is not consistent with atopic inflammation. Using EBBs, other investigators have demonstrated the presence of airway eosinophilia and airway remodelling at an early age in wheezing preschoolers with probable asthma $(15,16)$. In these studies, it is difficult to discern subgroups due to the lack of power, given the small number of subjects. Measurement of exhaled NO may help to distinguish children with probable asthma $(23,24)$.

Studies in children with asthma have shown heterogeneity in inflammatory patterns. These distinct inflammatory phenotypes likely result from different etiological pathways. Frequently, a phenotype is assigned on a single occasion and it is unknown whether this phenotype assignment is stable over time. Whether phenotype-specific treatment of asthma improves the management of childhood asthma is unknown.

\section{REFERENCES}

1. Wenzel SE. Asthma: Defining of the persistent adult phenotypes. Lancet 2006;368:804-13.

2. Gibson PG, Henry RL, Thomas P. Noninvasive assessment of airway inflammation in children: Induced sputum, exhaled nitric oxide, and breath condensate. Eur Respir J 2000;16:1008-15.

3. Grootendorst DC, Sont JK, Willems LN, et al. Comparison of inflammatory cell counts in asthma: Induced sputum vs bronchoalveolar lavage and bronchial biopsies. Clin Exp Allergy 1997;27:769-79.

4. Maestrelli P, Saetta M, Di Stefano A, et al. Comparison of leukocyte counts in sputum, bronchial biopsies, and bronchoalveolar lavage. Am J Respir Crit Care Med 1995;152:1926-31.

5. Lex C, Ferreira F, Zacharasiewicz A, et al. Airway eosinophilia in children with severe asthma: Predictive values of noninvasive tests. Am J Respir Crit Care Med 2006;174:1286-91.

6. Strunk RC, Szefler SJ, Phillips BR, et al. Relationship of exhaled nitric oxide to clinical and inflammatory markers of persistent asthma in children. J Allergy Clin Immunol 2003;112:883-92.

7. Jenkins HA, Cool C, Szefler SJ, et al. Histopathology of severe childhood asthma: A case series. Chest 2003;124:32-41.

8. de Blic J, Tillie-Leblond I, Tonnel AB, Jaubert F, Scheinmann P, Gosset P. Difficult asthma in children: An analysis of airway inflammation. J Allergy Clin Immunol 2004;113:94-100.

9. Payne DN, Rogers AV, Adelroth E, et al. Early thickening of the reticular basement membrane in children with difficult asthma. Am J Respir Crit Care Med 2003;167:78-82.

10. Payne DN, Qiu Y, Zhu J, et al. Airway inflammation in children with difficult asthma: Relationships with airflow limitation and persistent symptoms. Thorax 2004;59:862-9.

11. Cokugras H, Akcakaya N, Seckin, Camcioglu Y, Sarimurat N, Aksoy F. Ultrastructural examination of bronchial biopsy specimens from children with moderate asthma. Thorax 2001;56:25-9.

12. Barbato A, Turato G, Baraldo S, et al. Airway inflammation in childhood asthma. Am J Respir Crit Care Med 2003;168:798-803.

13. Barbato A, Turato G, Baraldo S, et al. Epithelial damage and angiogenesis in the airways of children with asthma. Am J Respir Crit Care Med 2006;174:975-81.

14. Pohunek P, Warner JO, Turzikova J, Kudrmann J, Roche WR. Markers of eosinophilic inflammation and tissue remodelling in children before clinically diagnosed bronchial asthma. Pediatr Allergy Immunol 2005;16:43-51.

15. Saglani S, Malmstrom K, Pelkonen AS, et al. Airway remodeling and inflammation in symptomatic infants with reversible airflow obstruction. Am J Respir Crit Care Med 2005;171:722-7.

16. Saglani S, Payne DN, Zhu J, et al. Early detection of airway wall remodeling and eosinophilic inflammation in preschool wheezers. Am J Respir Crit Care Med 2007;176:858-64. 
17. van den Toorn LM, Overbeek SE, de Jongste JC, Leman K, Hoogsteden HC, Prins JB. Airway inflammation is present during clinical remission of atopic asthma. Am J Respir Crit Care Med 2001;164:2107-13.

18. Warke TJ, Fitch PS, Brown V, et al. Outgrown asthma does not mean no airways inflammation. Eur Respir J 2002;19:284-7.

19. Stevenson EC, Turner G, Heaney LG, et al. Bronchoalveolar lavage findings suggest two different forms of childhood asthma. Clin Exp Allergy 1997;27:1027-35.

20. Marguet C, Jouen-Boedes F, Dean TP, Warner JO. Bronchoalveolar cell profiles in children with asthma, infantile wheeze, chronic cough, or cystic fibrosis. Am J Respir Crit Care Med 1999;159:1533-40.

21. Le Bourgeois M, Goncalves M, Le Clainche L, et al. Bronchoalveolar cells in children $<3$ years old with severe recurrent wheezing. Chest 2002;122:791-7.

22. Krawiec ME, Westcott JY, Chu HW, et al. Persistent wheezing in very young children is associated with lower respiratory inflammation. Am J Respir Crit Care Med 2001;163:1338-43.

23. Moeller A, Diefenbacher C, Lehmann A, et al. Exhaled nitric oxide distinguishes between subgroups of preschool children with respiratory symptoms. J Allergy Clin Immunol 2008;121:705-9.

24. Malmberg LP, Pelkonen AS, Haahtela T, Turpeinen M. Exhaled nitric oxide rather than lung function distinguishes preschool children with probable asthma. Thorax 2003;58:494-9.

\section{Immune modulation in the fetus and newborn: Strategies for asthma prevention}

\author{
Christine McCusker MD
}

\author{
Division of Allergy and Immunology, \\ Montreal Children's Hospital-McGill \\ University Health Centre, Montréal, Québec
}

W hen does asthma develop? This is an important question for investigators determined to prevent or, failing that, treat asthma in the earliest stages. Elements important in the etiology of allergic asthma include contact with environmental allergens, skewing of the subsequent immune response toward the development of the T-helper (Th) 2 phenotype, the development of airway hyper-responsiveness to both subsequent allergen contact as well as airway hypersensitivity to irritants and infectious agents, persistent chronic airway inflammation leading to chronic airway changes and persistent asthma symptoms (1).

Epidemiological studies have shown that early daycare attendance, high birth order, presence of pet allergens in the home and rural environments are protective against asthma (2), suggesting that the development of the allergic phenotype may be modifiable. However, evidence suggests that while predisposition to atopic asthma is multifactorial, involving complex gene-environment interactions, prevention of asthma development may be best achieved by interventions aimed at the first immune responses in the newborn and/or infant periods (3-5).

The fetal and neonatal immune systems differ significantly from that of adults. The prenatal and early neonatal immune responses are predisposed to follow a Th2 pathway $(6,7)$. In addition, signalling via innate receptors is less robust compared with adult responses (8), and there is a greater percentage of naive cells versus activated $T$ and $B$ cells. Finally, Th1 responses are attenuated with reduced production of interferon-gamma. Postnatal maturation of the immune system is driven by contact with antigen, and $\mathrm{T}$ cell differentiation may take different paths such as Th1, Th2, Th17 or T regulatory, depending on the stimulus (9). Maintenance of a predominantly Th2 response would predispose to the development of allergic airways later in life. In contrast, appropriate education of the newborn response and encouraging formation of $\mathrm{T}$ regulatory responses to common environmental antigens likely prevents the development of the allergic phenotype and subsequent asthma. The evidence suggests that the neonatal immune system can be influenced by environmental stimuli and, thus, appropriate exposure to antigens in the neonatal period may induce immune site-specific tolerance (1).

However, the following question arises: what are the factors determining the fate of $\mathrm{T}$ cells during any given immune response and which of these are involved in triggering the allergic response? $T$ cell activation begins with the entry of antigen into the mucosal environment, where it comes into contact with the pattern recognition receptors of the innate immune system. These receptors include the toll-like receptors (TLRs) and are capable of identifying elements such as bacterial cell walls, prokaryotic RNA and protein structures often found in pathogenic organisms. Triggering of the TLRs on both structural cells as well as circulating immune cells induces the production of cytokines and the upregulation of cell surface receptors on antigen-presenting cells such as dendritic cells and macrophages. During the subsequent interaction between the naive $T$ cell and dendritic cell, the $T$ cell receives information from both the cytokines released into the cellular milieu as well as from the receptors expressed by the dendritic cell, and is driven toward the development of a specific activation phenotype. For example, the presence of interleukin-4 in the cellular milieu, associated with specific arrays of receptors on the antigen-presenting cell, drives $\mathrm{T}$ cells toward the Th2 phenotype, while the presence of interleukin-12 and interferon-gamma induces Th1 responses. However, the understanding of the control of $\mathrm{T}$ cell fate is currently incomplete (8).

In neonatal animal models, the capacity for modulation of specific immune responses through antigen exposure in breast milk, and through early mucosal stimulation with antigen and a potent stimulator of TLR 4 - lipopolysaccharide (LPS) - has been demonstrated $(3,9)$. In one previous study, antigen-naive dams were exposed to inhaled antigen. Through breast milk, antigen was passed to the newborn. The presence of the cytokine transforming growth factor-beta in the milk induced lifelong antigen-specific tolerance (3). In another series of experiments, newborn mice were exposed to allergen or LPS. In adulthood, these mice mounted an allergen-induced nonallergic Th1 response on subsequent exposure to the same allergen. The LPS-exposed animals developed $\mathrm{T}$ regulatory cells in response to allergen sensitization in adulthood - in both instances, the animals failed to develop asthma (9).

Taken together, these data suggest that the newborn immune system requires stimulation to 'learn' how and when to respond to environmental stimuli. To prevent allergic airways disease, it may be necessary to develop early-life interventions. Understanding the short-and long-term impacts of environmental modification on the developing immune system may lead to strategies that prevent asthma in children and adults. 


\section{REFERENCES}

1. Holt PG, Sly PD. Prevention of allergic respiratory disease in infants: Current aspects and future perspectives. Curr Opin Allergy Clin Immunol 2007;7:547-55.

2. von Mutius E. Allergies, infections and the hygiene hypothesis the epidemiological evidence. Immunobiology 2007;212:433-9.

3. Verhasselt V, Milcent V, Cazareth J, et al. Breast milk-mediated transfer of an antigen induces tolerance and protection from allergic asthma. Nature Med 2008;14:170-5.

4. Zutavern A, von Klot S, Gehring U, et al. Prenatal and postnatal exposure to respiratory infection and atopic diseases development: A historical cohort study. Respir Res 2006; 7:81-9.

5. Rowe J, Kusel M, Holt BJ, et al. Prenatal versus postnatal sensitization to environmental allergens in a high-risk birth cohort. J Allergy Clin Immunol 2007;119:1164-73.

6. Miyazaki S, Tsuda H, Sakai M et al. Predominance of TH2promoting dendritic cells in early human pregnancy decidua. J Leukoc Biol 2003;74:514-22.

7. Adkins B, Bu Y, Guevara P. Murine neonatal CD4 $4^{+}$lymph node cells are highly deficient in the development of antigen-specific Th1 function in adoptive adult hosts. J Immunol 2002;169:4998-5004.

8. Levy O. Innate immunity of the newborn: Basic mechanisms and clinical correlates. Nat Rev Immunol 2007;7:379-90.

9. Wang Y, McCusker C. Neonatal exposure with LPS and/or allergen prevents experimental allergic airways disease: Development of tolerance using environmental antigens. J Allergy Clin Immunol 2006;118:143-51.

\section{Airway inflammation in cystic fibrosis}

\author{
Felix Ratjen MD \\ Hospital for Sick Children, Toronto, Ontario
}

C ystic fibrosis (CF) lung disease is characterized by neutrophilic airway inflammation that is pronounced and persistent $(1,2)$. There is ongoing controversy as to whether the cystic fibrosis transmembrane conductance regulator (CFTR) gene mutation itself causes a proinflammatory milieu in the airways or whether inflammation is always secondary to infection in CF (3). Studies in cell culture systems have yielded conflicting results. While initial data have shown increased nuclear factor-kappaB light chain-enhancer activation and interleukin (IL)-8 production in unstimulated CF epithelial cells, others have not confirmed this and found a higher inflammatory response only after infection with Pseudomonas aeruginosa (4-7). Fetal CF airways transplanted into severe combined immunodeficient mice demonstrate higher IL-8 concentrations and luminal invasion of neutrophils, despite the absence of pathogens $(8,9)$. Recent evidence using CFTR inhibitors in mice also supports the presence of a proinflammatory milieu (10). In addition to an exaggerated response to inflammatory stimuli, evidence also exists for defective downregulation of inflammation (11). However, it remains to be clarified whether a deficiency in anti-inflammatory cytokines is a primary or secondary event in CF lung disease (12).

Overall, this controversy is difficult to resolve in vivo because almost all CF patients have intermittent or chronic bacterial infection, and even viral infections alone have been shown to cause neutrophilic airway inflammation (12). This also implies that the controversy, while being of importance to define the underlying pathophysiological principle, is less relevant for the treatment of CF patients in whom inflammation is virtually universal. Our own bronchoalveolar lavage (BAL) studies (13) have demonstrated that the presence of airway inflammation is a risk factor for pulmonary function decline. All these data support the concept that the sustained and exaggerated inflammatory response in CF airways is an important component of CF lung disease and, therefore, a potential treatment target.

Most of the information regarding airway inflammation in CF stems from BAL studies, which highlights the problem that less invasive clinical tests have been less helpful in defining the extent of inflammation in the airways. Importantly, markers of systemic inflammation are usually negative in symptomatic CF patients despite the presence of sustained airway inflammation (14). Induced sputum is a less invasive test than BAL that has been used in clinical studies, and neutrophil and IL-8 concentrations have been shown to decrease after treatment of pulmonary exacerbations, indicating that sputum markers could potentially be used to monitor airway inflammation in interventional studies (15).

Different therapeutic approaches have been used to control or downregulate airway inflammation in CF. Because both infection and inflammation coexist in CF airways, aggressive anti-inflammatory approaches may exacerbate infection and negatively influence outcome - some recent studies would suggest this to be the case. Long-term, systemic corticosteroid treatment has been shown to have beneficial effects on lung function, but is associated with unacceptable side effects $(16,17)$. Furthermore, a recent study (18) did not support the use of steroids during an acute exacerbation. Inhaled corticosteroids are an attractive alternative, but the evidence does not support their use except for patients with an asthmatic component (19). High-dose ibuprofen was found to have a positive impact on lung function decline in two trials, but requires tight monitoring, which has limited its widespread use (20-22). Therefore, while studies have proven the concept that inflammation is an adequate treatment target in CF, the ideal compound that is both safe and efficacious remains unknown.

\section{REFERENCES}

1. Ratjen F, Döring G. Cystic fibrosis. Lancet 2003;361:681-9.

2. Gibson RL, Burns JL, Ramsey BW. Pathophysiology and management of pulmonary infections in cystic fibrosis. Am J Respir Crit Care Med 2003;168:918-51.

3. Armstrong DS, Hook SM, Jamsen KM, et al. Lower airway inflammation in infants with cystic fibrosis detected by newborn screening. Pediatr Pulmonol 2005;40:500-10.

4. Weber AJ, Soong G, Bryan R, Saba S, Prince A. Activation of NF-kappa B in airway epithelial cells is dependent on CFTR trafficking and $\mathrm{Cl}^{-}$channel function. Am J Physiol Lung Cell Mol Physiol 2001;281:L71-8.

5. Kube D, Sontich U, Fletcher D, Davis PB. Proinflammatory cytokine responses to $P$ aeruginosa infection in human airway epithelial cell lines. Am J Physiol Lung Cell Mol Physiol 2001;280:L493-502.

6. Aldallal N, McNaughton EE, Manzel LJ, et al. Inflammatory response in airway epithelial cells isolated from patients with cystic fibrosis. Am J Respir Crit Care Med 2002;166:1248-56.

7. Becker MN, Sauer MS, Muhlebach MS, et al. Cytokine secretion by cystic fibrosis airway epithelial cells. Am J Respir Crit Care Med 2004;169:645-53.

8. Tirouvanziam R, de Bentzmann S, Hubeau C, et al. Inflammation and infection in naive human cystic fibrosis airway grafts. Am J Respir Cell Mol Biol 2000;23:121-7.

9. Hubeau C, Lorenzato M, Couetil JP, et al. Quantitative analysis of inflammatory cells infiltrating the cystic fibrosis airway mucosa. Clin Exp Immunol 2001;124:69-76.

10. Perez A, Issler AC, Cotton CU, Kelley TJ, Verkman AS, Davis PB. CFTR inhibition mimics the cystic fibrosis inflammatory profile. Am J Physiol Lung Cell Mol Physiol 2007;292:L383-95. 
11. Bonfield TL, Konstan MW, Burfeind P, Panuska JR, Hilliard JB, Berger M. Normal bronchial epithelial cells constitutively produce the anti-inflammatory cytokine interleukin-10, which is downregulated in cystic fibrosis. Am J Respir Cell Mol Biol 1995;13:257-61.

12. Starosta V, Ratjen F, Rietschel E, Paul K, Griese M. Anti-inflammatory cytokines in cystic fibrosis lung disease. Eur Respir J 2006;28:581-7.

13. Paul K, Rietschel E, Ballmann M, et al; for the BEAT Study Group. Effect of dornase alpha on airway inflammation in cystic fibrosis. Am J Respir Care Med 2004;169:719-25.

14. Elizur A, Cannon CL, Ferkol TW. Airway inflammation in cystic fibrosis. Chest 2008;133:489-95.

15. Ordonez CL, Henig NR, Mayer-Hamblett N, et al. Inflammatory and microbiologic markers in induced sputum after intravenous antibiotics in cystic fibrosis. Am J Respir Crit Care Med 2003;168:1471-5.

16. Eigen H, Rosenstein BJ, Fitzsimmons S, et al. A multicenter study of alternate-day prednisone therapy in patients with cystic fibrosis. J Pediatr 1995;126:515-23.
17. Lai HC, FitzSimmons SC, Allen DB, et al. Risk of persistent growth impairment after alternate-day prednisone treatment in children with cystic fibrosis. N Engl J Med 2000;342:851-9.

18. Dovey M, Aitken ML, Emerson J, McNamara S, Waltz DA, Gibson RL. Oral corticosteroid therapy in cystic fibrosis patients hospitalized for pulmonary exacerbation: A pilot study. Chest 2007;132:1212-8.

19. Balfour-Lynn IM, Lees B, Hall P, et al; CF WISE (Withdrawal of Inhaled Steroids Evaluation) Investigators. Multicenter randomized controlled trial of withdrawal of inhaled corticosteroids in cystic fibrosis. Am J Respir Crit Care Med 2006;173:1356-62.

20. Konstan MW, Byard PJ, Hoppel CL, et al. Effect of high-dose ibuprofen in patients with cystic fibrosis. N Engl J Med 1995,332:848-54.

21. Lands LC, Milner R, Cantin AM, Manson D, Corey M. High-dose ibuprofen in cystic fibrosis: Canadian safety and effectiveness trial. J Pediatr 2007;151:249-54.

22. Bush A, Davies J. Non! to non-steroidal anti-inflammatory therapy for inflammatory lung disease in cystic fibrosis (at least at the moment). J Pediatr 2007;151:228-30. 


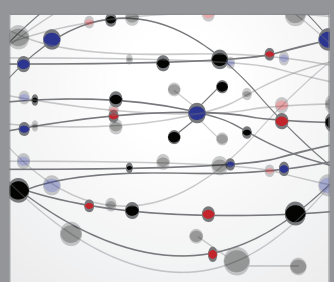

The Scientific World Journal
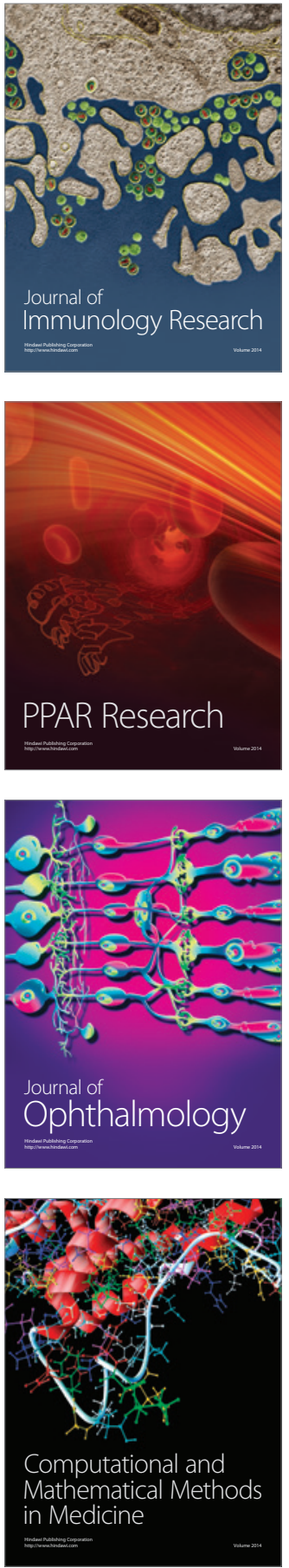

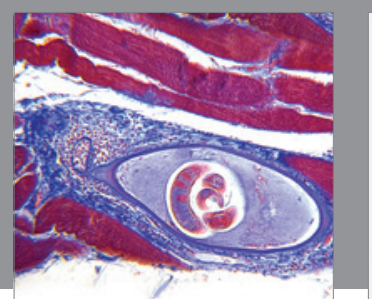

Gastroenterology Research and Practice

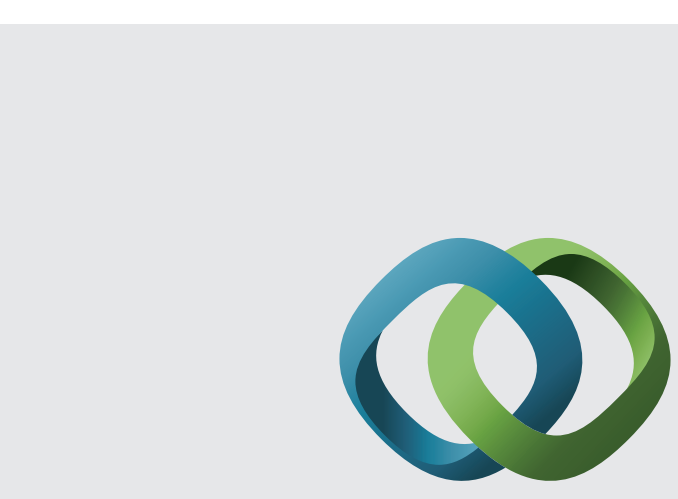

\section{Hindawi}

Submit your manuscripts at

http://www.hindawi.com
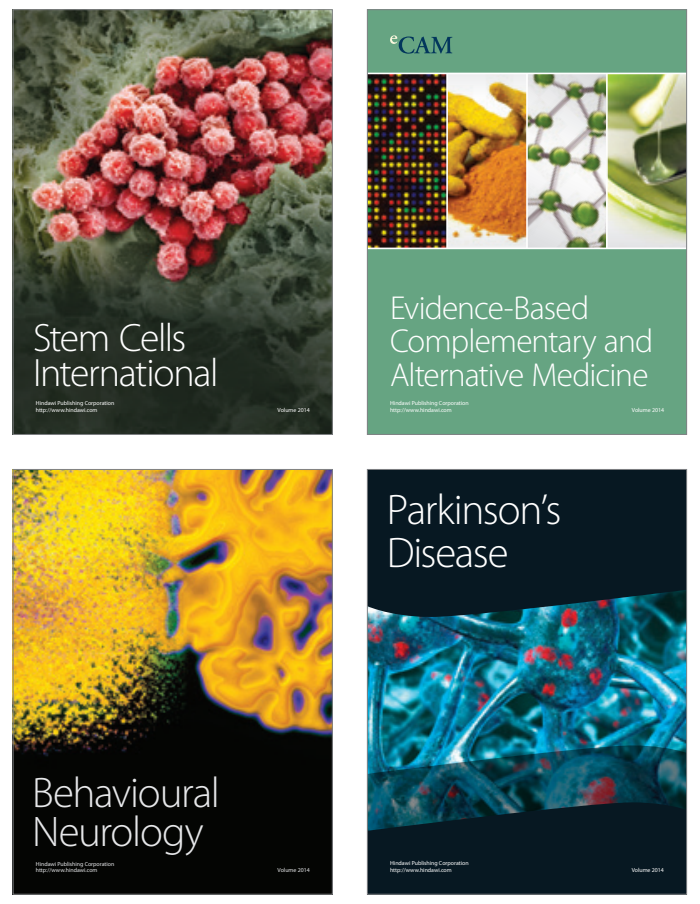
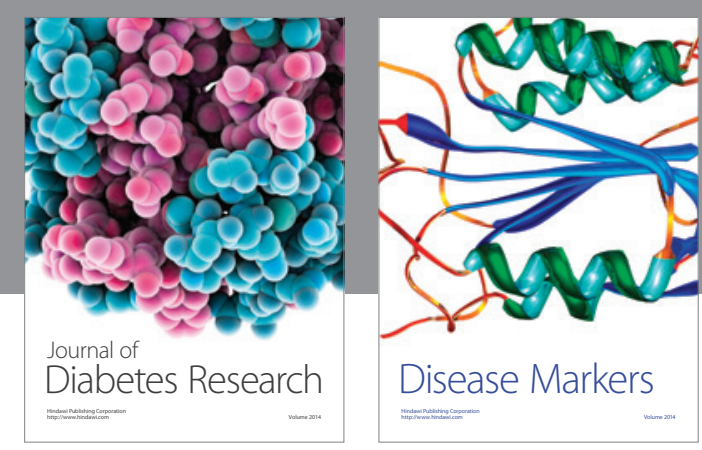

Disease Markers
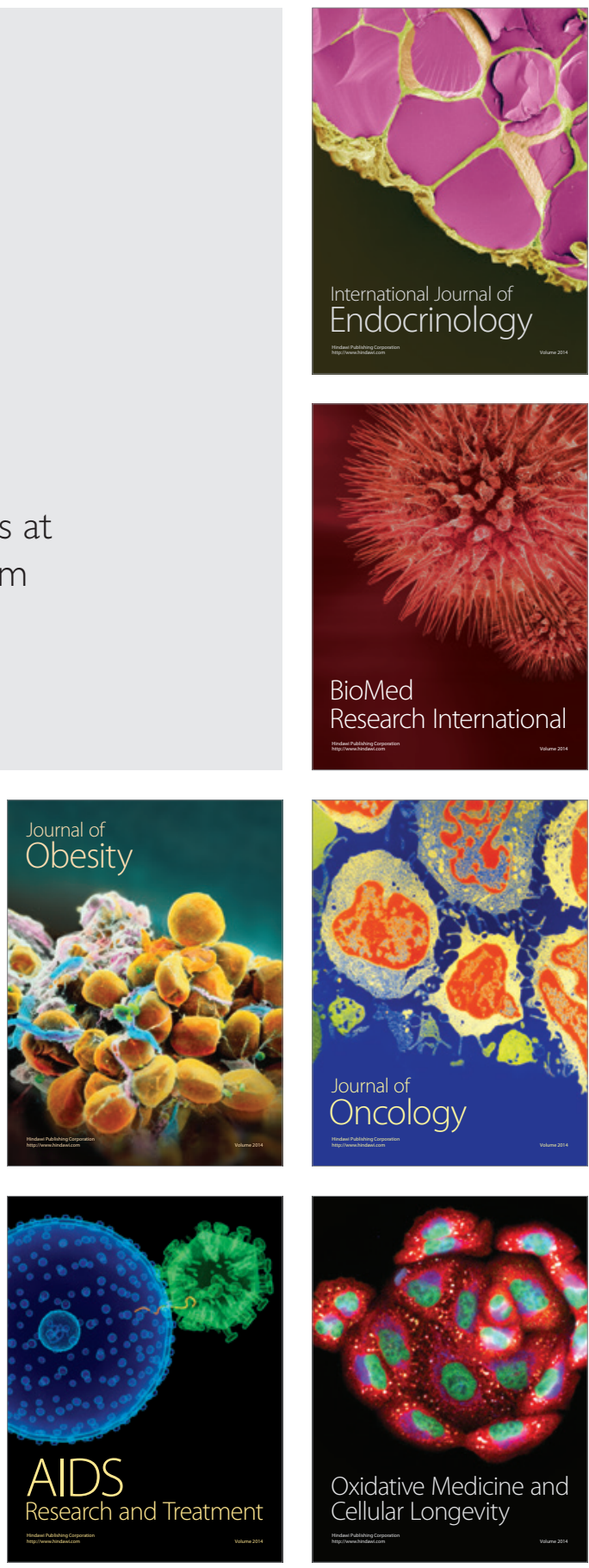